\title{
NUMERICAL MODELING OF THE PLANETARY BOUNDARY LAYER
}

\author{
P. Oliveira \\ J. Soares \\ H. A. Karam \\ M. M. R. Pereira \\ ABSTRACT \\ This work describes the major available techniques to simulate the time and \\ space evolution of the planetary boundary layer. For homogeneous and \\ equilibrium conditions the structure of the planetary boundary layer can be \\ diagnosed from the Monin-Obukhov, Free Convection, Local and Mixed \\ Layer Similarity theories. For the other atmospheric conditions the \\ planetary boundary layer can be numerically simulated using first and \\ second order closure models and large eddy models. The closure models \\ take into consideration the traditional statistical approach. Large eddy \\ simulation models are based on the filtered equations of motion and require \\ the statistical approach to estimate subgrid turbulence. \\ Institute of Astronomy, Geophysics and \\ Atmospheric Sciences \\ Department of Atmospheric Sciences \\ Group of Micrometeorology \\ Rua do Matão, 1226 \\ 05508-900, São Paulo, SP, Brazil \\ apdolive@usp.br
}

\section{INTRODUCTION}

The Planetary Boundary Layer (PBL) is the region of the atmosphere, adjacent to the surface, where turbulence is the dominant feature. The intensity of turbulence determines the spatial distribution of thermodynamic and dynamic properties in the PBL as well as its vertical extent. Over continental areas, the turbulence is maintained by wind shear throughout the day, and it is intensified by thermal convection, during daytime, and restrained by surface inversion layer during nighttime. Its vertical extent varies from 300-1500 m, during day, to 100$300 \mathrm{~m}$ at night. Over the ocean the thermal effects on the turbulence is much less important and its vertical extent has smaller amplitude compared to the continental areas (Garrat, et al. 1996). Improving the understanding of PBL is important for several human activities: weather forecasting, pollution management, agriculture, etc. The PBL properties can be described by application of numerical and physical modeling. The numerical models are based on numerical solution of momentum, thermodynamic and mass conservation laws (Wyngaard, 1985). Physical modeling of the PBL is accomplished by wind tunnels and convection tank. (Cermark 1995; Lu and Arya, 1995; Avissar et al, 1990). In this paper the major techniques used to model numerically the PBL will be reviewed, and some numerical results will be shown.

\section{PBL MODELS}

Turbulent flow can be simulated numerically by solving directly the equations of motion discretized over a mesh (She, et al. 1991). The number of grid points required to describe a turbulent flow with characteristic length scale $\lambda$ is given by $(\lambda / \eta)^{3}$, where $\eta$ is the Kolmogorov microscale. It can be shown that the number of grid points is proportional to the Reynolds number $(\mathrm{Re})$ of the flow according to the $(\lambda / \eta)^{3} \approx \operatorname{Re}^{9 / 4}$. Applying direct numeric simulation (DNS) to simulate the PBL would require, for typical conditions $(\lambda=1000 \mathrm{~m}$ and $\eta=0.001 \mathrm{~m})$ about $10^{27}$ grid points. This simple result indicates that DNS cannot be applied to simulate PBL.

The turbulent flows can be (and have been) adequately described by statistical methods. The hypothesis is that each dynamic and thermodynamic properties of the flow can be treated as a random variable (Monin and Yaglon, 1971; Frisch, 1995). The concept of ensemble average, or Reynolds average, is then applied to derive the prognostic mean equations of motion necessary to describe the statistical properties of the PBL (Stull, 1988).

Table 1. The Reynolds averaged momentum and thermodynamic equations used to describe the atmosphere mean state of a horizontally homogeneous PBL.

\begin{tabular}{|c|c|}
\hline Equation & Unknown \\
\hline$\frac{\partial \overline{\mathrm{u}}}{\partial \mathrm{t}}=-\frac{\partial \overline{\left(\mathrm{u}^{\prime} \mathrm{w}^{\prime}\right)}}{\partial \mathrm{z}}+\left(-\frac{1}{\rho_{\mathrm{o}}} \frac{\partial \overline{\mathrm{p}}}{\partial \mathrm{x}}+\mathrm{f} \overline{\mathrm{v}}\right)$ & $\overline{\mathrm{u}}, \overline{\left(\mathrm{u}^{\prime} \mathrm{w}^{\prime}\right)}$ \\
\hline$\frac{\partial \overline{\mathrm{v}}}{\partial \mathrm{t}}=-\frac{\partial \overline{\left(\mathrm{v}^{\prime} \mathrm{w}^{\prime}\right)}}{\partial \mathrm{z}}+\left(-\frac{1}{\rho_{\mathrm{o}}} \frac{\partial \overline{\mathrm{p}}}{\partial \mathrm{y}}-\mathrm{f} \overline{\mathrm{u}}\right)$ & $\overline{\mathrm{v}}, \overline{\left(\mathrm{v}^{\prime} \mathrm{w}^{\prime}\right)}$ \\
\hline$\frac{\partial \bar{\theta}}{\partial \mathrm{t}}=-\frac{\partial \overline{\left(\theta^{\prime} \mathrm{w}^{\prime}\right)}}{\partial \mathrm{z}}-\left(\frac{1}{\rho_{0} \mathrm{c}_{\mathrm{P}}} \frac{\partial \mathrm{R}_{\mathrm{N}}}{\partial \mathrm{z}}\right)$ & $\bar{\theta}, \overline{\left(\theta^{\prime} \mathrm{w}^{\prime}\right)}$ \\
\hline
\end{tabular}

This work focuses on the PBL mean properties associated to the zonal and meridional components of the wind $(\overline{\mathrm{u}}, \overline{\mathrm{v}})$ and mean potential temperature $(\bar{\theta})$. The overbar indicates Reynolds average. The momentum and thermodynamic conservation laws applied to atmosphere can be simplified, considering the air as an ideal gas, resulting into a set of 3 equations as illustrated in Table 1. 
There, the symbols $-1 / \rho_{\mathrm{o}}(\partial \overline{\mathrm{p}} / \partial \mathrm{y})$ and $-1 / \rho_{\mathrm{o}}(\partial \overline{\mathrm{p}} / \partial \mathrm{x})$ indicate the horizontal mean pressure gradient acceleration in the $\mathrm{x}$ and $\mathrm{y}$ directions, where $\rho_{0}$ is basic state atmospheric density; $-\mathrm{f} \overline{\mathrm{v}}$ and $-\mathrm{f} \overline{\mathrm{u}}$ are the Coriolis acceleration, where $\mathrm{f}$ is the Coriolis parameter; $\overline{\left(\mathrm{u}^{\prime} \mathrm{w}^{\prime}\right)}$ and $\overline{\left(\mathrm{v}^{\prime} \mathrm{w}^{\prime}\right)}$ are vertical turbulent fluxes of momentum; $\overline{\left(\theta^{\prime} \mathrm{w}^{\prime}\right)}$ is the vertical turbulent flux of sensible heat; $\left(-1 / \rho_{0} c_{P}\right)\left(\partial R_{N} / \partial z\right)$ is the vertical divergence of the net radiation flux, where $c_{p}$ is the air specific heat at constant pressure. The thermodynamic equation is commonly expressed in terms of potential temperature, which is, by definition, the temperature that any air parcel would have if it was brought adiabatically to the level pressure of 1000 $\mathrm{hPa}\left(p_{00}\right)$. It can be estimated by $\theta=\mathrm{T}\left(\mathrm{p} / \mathrm{p}_{\infty}\right)^{\mathrm{R} / \mathrm{c}_{\mathrm{p}}}$, where $\mathrm{T}$ and $\mathrm{p}$ are the temperature and pressure of the air parcel and $R_{D}$ is the dry air gas constant.

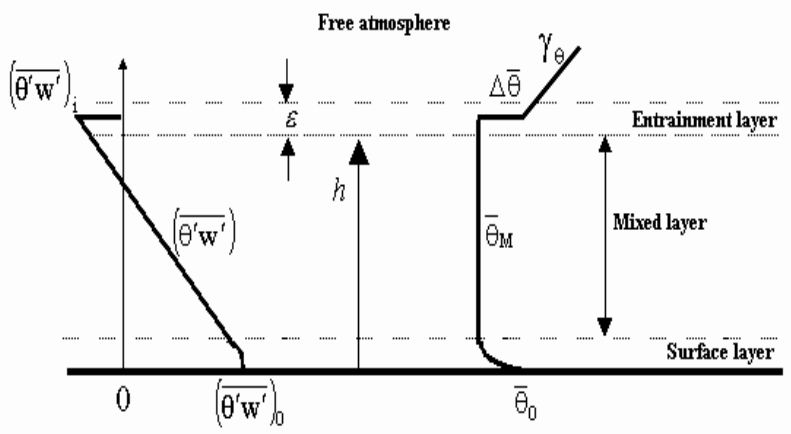

Figure 1. Schematic description the bulk model thermodynamic structure for convective PBL.

The advection terms in the motion equations (Table 1) were dropped because it is assumed that: (i) the PBL is homogeneous in the horizontal directions; (ii) the mean vertical velocity $(\overline{\mathrm{w}})$ is equal zero. For horizontally homogeneous PBL the mean flow is basically twodimensional. The accelerations associated to the horizontal component of pressure gradients, $-1 / \rho_{\mathrm{o}}(\partial \overline{\mathrm{p}} / \partial \mathrm{x})$ and $-1 / \rho_{\mathrm{o}}(\partial \overline{\mathrm{p}} / \partial \mathrm{y})$, are kept because they represent the external forcing associated to meteorological disturbances in spatial scales larger than those used to consider the PBL horizontally homogeneous (Stull, 1988). Above the PBL, in the free atmosphere (Fig. 1) the turbulent flux are negligible and the atmosphere is in geostrophic equilibrium, so that the horizontal wind can be represented by $\overline{\mathrm{u}}_{\mathrm{g}}=-1 / \mathrm{f} \rho_{\mathrm{o}}(\partial \overline{\mathrm{p}} / \partial \mathrm{y})$ and $\overline{\mathrm{v}}_{\mathrm{g}}=+1 / \mathrm{f} \rho_{\mathrm{o}}(\partial \overline{\mathrm{p}} / \partial \mathrm{x})$, at least in the middle latitudes. Therefore, as the PBL evolves, the geostrophic equilibrium is disrupted by turbulent friction, $-\partial \overline{\left(u^{\prime} w^{\prime}\right)} / \partial z$ and $-\partial \overline{\left(v^{\prime} w^{\prime}\right)} / \partial z$, which decelerates the horizontal components of the mean wind.
Table 2. Characteristic scales used in the Monin-Obukhov and Free Convection similarity valid for the Atmospheric Surface Layer. $\kappa$ is the von Karman constant.

\begin{tabular}{|c|c|c|}
\hline $\begin{array}{c}\text { Characteristic } \\
\text { scale }\end{array}$ & Monin-Obukhov & Free convection \\
\hline Wind Velocity & $\mathrm{u}_{*}=\sqrt[4]{\left(\overline{\left(\mathrm{u}^{\prime} \mathrm{w}^{\prime}\right)_{0}^{2}}+\overline{\left(\mathrm{u}^{\prime} \mathrm{w}^{\prime}\right)_{0}^{2}}\right.}$ & $\mathrm{u}_{\mathrm{F}}=\left[\kappa \frac{\mathrm{g}}{\theta_{0}} \overline{\left(\mathrm{w}^{\prime} \theta^{\prime}\right)_{0} \mathrm{z}}\right]^{1 / 3}$ \\
\hline Temperature & $\theta_{*}=-\overline{\left(\theta^{\prime} \mathrm{w}^{\prime}\right)_{0}} / \mathrm{u}_{*}$ & $\theta_{\mathrm{F}}=\overline{\left(\theta^{\prime} \mathrm{w}^{\prime}\right)_{0}} / \mathrm{u}_{\mathrm{F}}$ \\
\hline Length & $\mathrm{L}=-\mathrm{u}_{*}^{3} /\left(\kappa \frac{\mathrm{g}}{\theta_{0}} \overline{\left(\mathrm{w}^{\prime} \theta^{\prime}\right)_{0}}\right)$ & $\mathrm{Z}$ \\
\hline
\end{tabular}

The temporal and spatial evolution of potential temperature in the free atmosphere is given by the radiation cooling or heating. In the PBL, the divergence of turbulent sensible heat, $-\partial \overline{\left(\theta^{\prime} \mathrm{w}^{\prime}\right)} / \partial \mathrm{z}$, will warm up the lower atmosphere, during daytime, and cool down, during nighttime, as result of the daytime solar heating of the surface and long wave radiation cooling during nighttime, respectively. It should be emphasized that the set of equations in Table 1 implies also that the mean flow, in the vertical direction, is in hydrostatic balance expressed by: $\mathrm{g}=-1 / \rho_{\mathrm{o}}(\partial \overline{\mathrm{p}} / \partial \mathrm{z})$, where $\mathrm{g}$ is the gravity acceleration. The set of motion equations in Table 1 reflects also the Boussinesq approximation, where the mean flow is nondivergent, $\partial \overline{\mathbf{u}} / \partial \mathbf{x}+\partial \overline{\mathrm{v}} / \partial \mathrm{y}+\partial \overline{\mathrm{w}} / \partial \mathbf{z}=0$, the equation of state is given by $\bar{\rho} / \rho_{0}=-\bar{\theta} / \theta_{0}$, with $\theta_{0}$ being the basic state atmospheric potential temperature. The basic state is also assumed to obey the ideal gas law $\mathrm{p}_{0}=\rho_{0} \mathrm{R}_{\mathrm{d}} \mathrm{T}_{0}$ (Dutton and Fitchl, 1969, Mahrt, 1986). The resulting set of equations used to describe the mean state suffers from the closure problem - the number of unknowns is larger than the number of equations (Table 1). To overcome the closure problem four approaches have been developed: (a) similarity laws; (b) bulk model, (c) first and superior order closure schemes and (d) Large eddy simulation models.

\section{SIMILARITY LAWS}

The similarity laws are derived from the observational fact that under certain conditions, the turbulence is intense enough to adjust itself to the surface and the external forcing changes fast enough so that the statistical properties of the PBL are in equilibrium. Under this frequent condition, the PBL properties are self-similar when normalized by appropriated characteristic scales. In the PBL, Monin-Obukhov, Free Convection, Mixed Layer and Local (or Z-less) are the similarities most celebrated by use (Sorbjan, 1989). They are known as similarity laws and are based on a set of empirical expressions developed to diagnose statistic properties of the turbulent flow like mean horizontal wind velocity $\left[\overline{\mathrm{V}}=\sqrt{\overline{\mathrm{u}}^{2}+\overline{\mathrm{v}}^{2}}\right]$, mean potential temperature $[\bar{\theta}]$, variances of the wind components $\left[\sigma_{u}^{2}=\overline{\left(u^{\prime} u^{\prime}\right)}, \quad \sigma_{v}^{2}=\overline{\left(v^{\prime} v^{\prime}\right)}, \quad \sigma_{w}^{2}=\overline{\left(w^{\prime} w^{\prime}\right)},\right], \quad$ variance of potential temperature $\left[\sigma_{\theta}^{2}=\overline{\left(\theta^{\prime} \theta^{\prime}\right)}\right]$, co-variances $\left[\overline{\left(u^{\prime} w^{\prime}\right)}\right.$, $\left.\overline{\left(v^{\prime} w^{\prime}\right)}, \overline{\left(\theta^{\prime} u^{\prime}\right)}, \overline{\left(\theta^{\prime} v^{\prime}\right)}, \overline{\left(\theta^{\prime} w^{\prime}\right)}\right]$ as well as their spectral and co-spectral distribution in the frequency space. 
The Monin-Obukhov and free convection similarities are valid for the surface layer (Fig. 1) and for stability conditions typically observed in this PBL layer. The characteristic scales of wind, temperature and length are respectively, $\mathrm{u}_{*}, \theta_{*}, \mathrm{z}$ and $\mathrm{L}$ for the Monin-Obukhov and $\mathrm{u}_{\mathrm{F}}, \theta_{\mathrm{F}}$ and $\mathrm{z}$ for free convection (Table 2).

Table 3. Characteristic scales used in the Mixed Layer and Local Similarity valid for the Convective and Stable Planetary Boundary layer.

\begin{tabular}{|c|c|c|}
\hline $\begin{array}{c}\text { Characteristic } \\
\text { scale }\end{array}$ & Mixed layer & Local \\
\hline Wind Velocity & $\mathrm{w}_{*}=\left[\frac{\mathrm{g}}{\theta_{0}} \overline{\left(\mathrm{w}^{\prime} \theta^{\prime}\right)_{0}} \mathrm{z}_{\mathrm{i}}\right]^{1 / 3}$ & $\mathrm{u}_{\mathrm{E}}=\sqrt[4]{{\overline{\left(\mathrm{u}^{\prime} \mathrm{w}^{\prime}\right)^{2}}+\overline{\left(\mathrm{u}^{\prime} \mathrm{w}^{\prime}\right)}}^{2}}$ \\
\hline Temperature & $\Theta_{*}=\overline{\left(\theta^{\prime} \mathrm{w}^{\prime}\right)_{0}} / \mathrm{w}_{*}$ & $\theta_{\mathrm{E}}=-\overline{\left(\theta^{\prime} \mathrm{w}^{\prime}\right)} / \mathrm{u}_{\mathrm{E}}$ \\
\hline Length & $\mathrm{Z}_{\mathrm{i}}$ & $\Lambda=-\mathrm{u}_{\mathrm{E}}^{3} /\left[\kappa \frac{\mathrm{g}}{\theta_{0}} \overline{\left(\theta^{\prime} \mathrm{w}^{\prime}\right)}\right]$ \\
\hline
\end{tabular}

In Figure 1, the vertical extent of the PBL is indicated by $\mathrm{h}$. The PBL potential temperature in the mixed layer is constant and indicated by $\bar{\theta}_{\mathrm{M}}$. The potential temperature at the surface is indicated by $\bar{\theta}_{0}$. The intensity of temperature inversion at the top of the mixed layer is given by $\Delta \bar{\theta}=\bar{\theta}(\mathrm{h}+\varepsilon / 2)-\bar{\theta}_{\mathrm{M}}$, where $\varepsilon$ is the depth of the entrainment layer. Above the PBL, the vertical rate of potential temperature variation is indicated by $\gamma_{\theta}$. The turbulent sensible heat flux varies linearly across the mixed layer from $\overline{\left(\theta^{\prime} \mathrm{w}^{\prime}\right)_{0}}$, in the surface layer, to $\overline{\left(\theta^{\prime} \mathrm{w}^{\prime}\right)_{\mathrm{i}}}$, in the entrainment layer.

The Monin-Obukhov similarity should be used when the surface layer (SL) turbulence structure is predominantly sustained by mechanical production and thermal production (or destruction) can have an important role. When the mechanical production is no important and the SL turbulence structure is sustained basically by the thermal production, the Free Convection similarity should by used in the SL.

The Mixed Layer and Local similarities are valid for regions of the PBL well above the SL. The Mixed Layer Similarity has successfully been applied to diagnose the vertical variance of wind velocity components and potential temperature in the convective PBL (Hojstrup, 1982). It is a generalization of the Free Convection similarity to regions above the SL where the characteristic length scale $\mathrm{z}_{\mathrm{i}}$ is given by the height of the convective PBL (Sorbjan, 1989). In the Mixed Layer, the characteristic scales of wind and temperature and length are, respectively, $\mathrm{w}_{*}, \Theta_{*}$ and $\mathrm{z}_{\mathrm{i}}$ (Table 3 ).
Table 4. Equations used in the bulk models.

\begin{tabular}{|c|c|}
\hline Bulk equation & Unknown \\
\hline$\frac{\partial \overline{\mathrm{u}}_{\mathrm{M}}}{\partial \mathrm{t}}=-\frac{\left[\overline{\left(\mathrm{u}^{\prime} \mathrm{w}^{\prime}\right)_{\mathrm{i}}}-\overline{\left(\mathrm{u}^{\prime} \mathrm{w}^{\prime}\right)_{0}}\right]}{\mathrm{h}}+\mathrm{f}\left(\overline{\mathrm{v}}_{\mathrm{M}}-\overline{\mathrm{v}}_{\mathrm{g}}\right)$ & $\overline{\mathrm{u}}_{\mathrm{M}}$ \\
\hline$\frac{\partial \bar{v}_{M}}{\partial t}=-\frac{\left[\overline{\left(\bar{v}^{\prime} w^{\prime}\right)_{i}}-\overline{\left(v^{\prime} w^{\prime}\right)_{0}}\right]}{h}-f\left(\bar{u}_{M}-\bar{u}_{g}\right)$ & $\overline{\mathrm{v}}_{\mathrm{M}}$ \\
\hline$\frac{\partial \bar{\theta}_{\mathrm{M}}}{\partial \mathrm{t}}=-\frac{\left[\overline{\left(\bar{\theta}^{\prime} \mathrm{w}^{\prime}\right)_{\mathrm{i}}}-\overline{\left(\theta^{\prime} \mathrm{w}^{\prime}\right)_{0}}\right]}{\mathrm{h}}$ & $\bar{\theta}_{\mathrm{M}}$ \\
\hline
\end{tabular}

\begin{tabular}{|c|c|}
\hline \multicolumn{2}{|l|}{ Entrainment layer equation } \\
\hline$\frac{\partial \Delta \overline{\mathrm{u}}}{\partial \mathrm{t}}=\frac{\left\lfloor\overline{\left(\mathrm{u}^{\prime} \mathrm{w}^{\prime}\right)_{\mathrm{i}}}-\overline{\left(\mathrm{u}^{\prime} \mathrm{w}^{\prime}\right)_{0}}\right\rfloor}{\mathrm{h}}+\mathrm{f} \Delta \overline{\mathrm{v}}$ & $\Delta \overline{\mathrm{u}}$ \\
\hline$\frac{\partial \Delta \overline{\mathrm{v}}}{\partial \mathrm{t}}=\frac{\left\lfloor\overline{\left(\mathrm{v}^{\prime} \mathrm{w}^{\prime}\right)_{\mathrm{i}}}-\overline{\left(\mathrm{v}^{\prime} \mathrm{w}^{\prime}\right)_{0}}\right\rfloor}{\mathrm{h}}-\mathrm{f} \Delta \overline{\mathrm{u}}$ & $\Delta \overline{\mathrm{V}}$ \\
\hline$\frac{\partial \Delta \bar{\theta}}{\partial \mathrm{t}}=\frac{\partial \mathrm{h}}{\partial \mathrm{t}} \gamma_{\theta}+\frac{\left[\overline{\left(\theta^{\prime} \mathrm{w}^{\prime}\right)_{\mathrm{i}}}-\overline{\left(\theta^{\prime} \mathrm{w}^{\prime}\right)_{0}}\right]}{\mathrm{h}}$ & $\Delta \bar{\theta}$ \\
\hline \multicolumn{2}{|l|}{ PBL height equation } \\
\hline$\frac{\partial \mathrm{h}}{\partial \mathrm{t}}=-\frac{\overline{\left(\mathrm{u}^{\prime} \mathrm{w}^{\prime}\right)_{\mathrm{i}}}}{\Delta \overline{\mathrm{u}}}=-\frac{\overline{\left(\mathrm{v}^{\prime} \mathrm{w}^{\prime}\right)_{\mathrm{i}}}}{\Delta \overline{\mathrm{v}}}=-\frac{\overline{\left(\theta^{\prime} \mathrm{w}^{\prime}\right)_{i}}}{\Delta \bar{\theta}}$ & $\mathrm{h}$ \\
\hline \multicolumn{2}{|l|}{ Closure equation } \\
\hline$\frac{\overline{\left(\theta^{\prime} w^{\prime}\right)_{i}}}{\overline{\left(\theta^{\prime} w^{\prime}\right)_{0}}}=-\frac{\overline{\left(u^{\prime} w^{\prime}\right)_{i}}}{\overline{\left(u^{\prime} w^{\prime}\right)_{0}}}=-\frac{\overline{\left(u^{\prime} w^{\prime}\right)_{i}}}{\overline{\left(u^{\prime} w^{\prime}\right)_{0}}}=\beta$ & $\begin{array}{l}\overline{\left(\theta^{\prime} \mathrm{w}^{\prime}\right)_{0}}, \\
\overline{\left(\mathrm{u}^{\prime} \mathrm{w}^{\prime}\right)_{0}}, \\
\overline{\left(\mathrm{v}^{\prime} \mathrm{w}^{\prime}\right)_{0}}\end{array}$ \\
\hline
\end{tabular}

The Local Similarity was developed by Nieuwstadt (1984) and used to PBL under stable conditions (occurring during night time over continental areas) when the turbulence is continuous. It can be understood as a generalization of the Monin-Obukhov Similarity to regions above the SL where the characteristic scales of wind, temperature and length - respectively, $\mathrm{u}_{\mathrm{E}}, \theta_{\mathrm{E}}$, and $\Lambda$ are estimated in terms of the local values of vertical turbulent fluxes of sensible heat and horizontal wind (Table 3). This particularity confers to the Local Similarity the ZLess characters (Wyngaard, 1985).

\section{BULK MODELS}

The bulk models are based on the integrated version of the motion equations (Table 4) assuming that when the intensity of the vertical turbulent mixing is large the mean properties of the flow are vertically homogeneous in large portion of the PBL. This is typically found over the continental areas and during daytime period. However, intense vertical turbulent mixing can be found during night time over continental areas due to large horizontal wind but it is a much less frequent situation. 


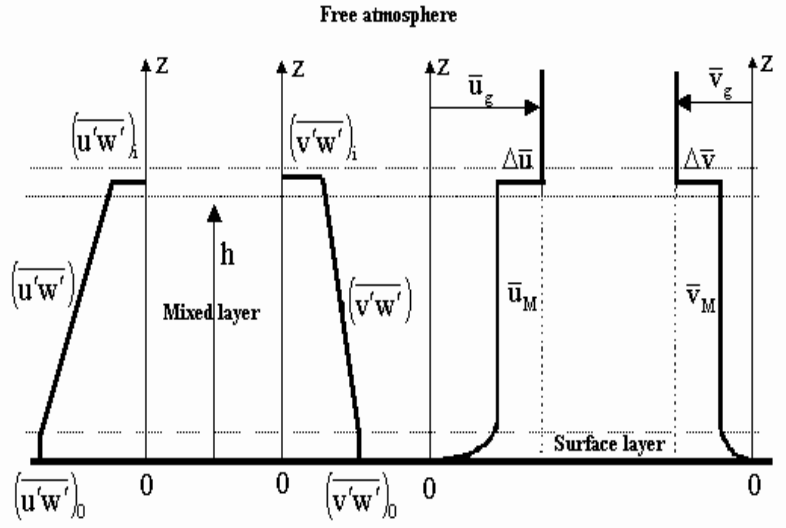

Figure 2. Schematic description the bulk model dynamic structure for convective PBL.
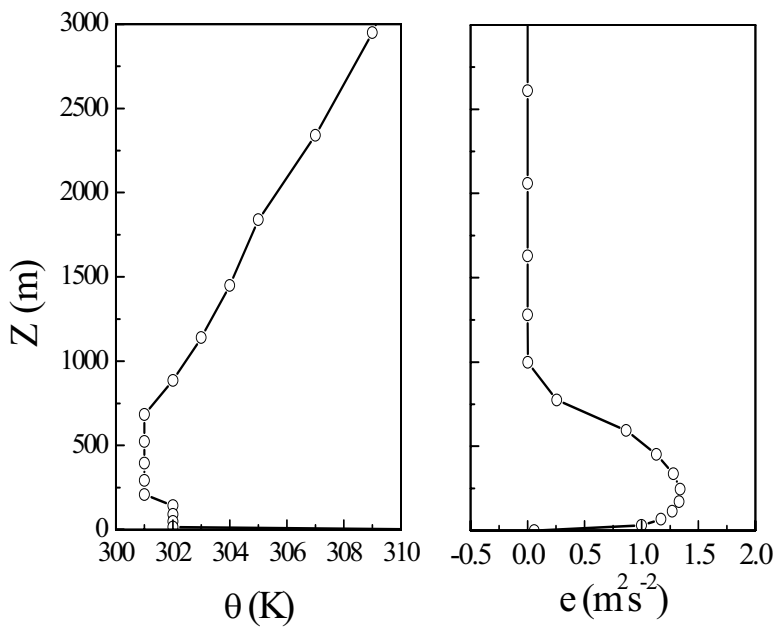

Figure 3. Vertical profile of temperature and turbulent kinetic energy simulated numerically using first order closure coupled to turbulent kinetic energy equation (TVM model). The profile corresponds the 12:00 LT in Iperó, São Paulo, during winter (Karam, et al., 2001).

The closure problem is overcome, in the case of the bulk models, by using the turbulent kinetic energy equation and considering similarity laws for convective case (Deardorff, 1980). The bulk model is very easy to implement numerically and admits analytical solution to estimate the height of the convective PBL (Oliveira et al, 1998): $\mathrm{h}(\mathrm{t})=\sqrt{\left(14 \int_{\mathrm{t}_{0}}^{\mathrm{t}}\left(\overline{{\theta^{\prime} \mathrm{w}^{\prime}}^{\prime}}\right)_{0} \mathrm{dt} /\left(5 \gamma_{\theta}\right)\right)}$, where the symbols used here are described in Figs 1 and 2. Besides it can be used as tool to understand the behavior of the well-mixed PBL.

In Fig.2, the mixed layer horizontal wind components are indicated by $\overline{\mathrm{u}}_{\mathrm{M}}$ and $\overline{\mathrm{v}}_{\mathrm{M}}$. The vertical turbulent fluxes of the components of horizontal wind at the top of the mixed layer are indicated by $\overline{\left(u^{\prime} w^{\prime}\right)_{i}}$ and $\overline{\left(v^{\prime} w^{\prime}\right)_{i}}$. The respective wind shear across the entrainment layer are indicated by $\Delta \overline{\mathrm{u}}=\overline{\mathrm{u}}_{\mathrm{g}}(\mathrm{h}+\varepsilon / 2)-\overline{\mathrm{u}}_{\mathrm{M}} \quad$ and $\Delta \overline{\mathrm{v}}=\overline{\mathrm{v}}_{\mathrm{g}}(\mathrm{h}+\varepsilon / 2)-\overline{\mathrm{v}}_{\mathrm{M}}$.

\section{FIRST ORDER CLOSURE}

The first order closure model of the PBL is based on the analogy between turbulent and molecular transports of the property. Therefore, the PBL turbulent fluxes can be written as given in Table 5 , where $\mathrm{K}_{\mathrm{M}}$ and $\mathrm{K}_{\mathrm{H}}$ are, respectively, the momentum and heat coefficients of turbulent diffusivity in the vertical direction.

Table 5. Equations used in the first order closure models.

\begin{tabular}{|c|c|}
\hline$\frac{\partial \overline{\mathrm{u}}}{\partial \mathrm{t}}=\frac{\partial}{\partial \mathrm{z}}\left(\mathrm{K}_{\mathrm{M}} \frac{\partial \overline{\mathrm{u}}}{\partial \mathrm{z}}\right)+\left(-\frac{1}{\rho_{\mathrm{o}}} \frac{\partial \overline{\mathrm{p}}}{\partial \mathrm{x}}+\mathrm{f} \overline{\mathrm{v}}\right)$ & $\overline{\mathrm{u}}, \mathrm{K}_{\mathrm{M}}$ \\
\hline$\frac{\partial \overline{\mathrm{v}}}{\partial \mathrm{t}}=\frac{\partial}{\partial \mathrm{z}}\left(\mathrm{K}_{\mathrm{M}} \frac{\partial \overline{\mathrm{v}}}{\partial \mathrm{z}}\right)+\left(-\frac{1}{\rho_{\mathrm{o}}} \frac{\partial \overline{\mathrm{p}}}{\partial \mathrm{y}}-\mathrm{f} \overline{\mathrm{u}}\right)$ & $\overline{\mathrm{v}}, \mathrm{K}_{\mathrm{M}}$ \\
\hline$\frac{\partial \bar{\theta}}{\partial \mathrm{t}}=\frac{\partial}{\partial \mathrm{z}}\left(\mathrm{K}_{\mathrm{H}} \frac{\partial \bar{\theta}}{\partial \mathrm{z}}\right)-\left(\frac{1}{\rho_{0} \mathrm{c}_{\mathrm{P}}} \frac{\partial \overline{\mathrm{R}}_{\mathrm{N}}}{\partial \mathrm{z}}\right)$ & $\bar{\theta}, \mathrm{K}_{\mathrm{H}}$ \\
\hline
\end{tabular}

The number of expressions used to estimate $\mathrm{K}_{\mathrm{M}}$ and $\mathrm{K}_{\mathrm{H}}$ in the atmospheric applications is very large (Holt and Raman, 1988) and most of them are based on the mixing length approach (Table 6). While they have gained a great popularity among the modeling community in the 60 's and yearly 70's, the first order closure model based on parameterizations of $\mathrm{K}_{\mathrm{M}}$ and $\mathrm{K}_{\mathrm{H}}$ in terms of mixing length and mean properties has been progressively substituted by parameterizations taking into consideration the turbulent kinetic energy equation (Table 7).

An example of numerical simulation of PBL vertical structure is given in the Fig. 3. The vertical profile of potential temperature indicates a mixed layer about 750 $m$ deep and the vertical extent of the PBL can be identified in the vertical profile of turbulent kinetic energy. These results are obtained using the mesoscale model TVM (Stivari et al., 2003). The TVM is a three-dimension model which takes into consideration topography and land use of the surface.

\section{SECOND ORDER CLOSURE MODEL (SOCM)}

The second order closure models are based on the set of equations that describe the second order statistical moments for momentum and temperature. The second order closure is carried for four terms: third order statistical momentum (or turbulent fluxes of second order statistical moments); pressure-velocity fluctuations correlation; tendency toward isotropy and molecular dissipation. In general, the parameterization of all these terms requires a particular mixing length. To overcome this problem, Mellor and Yamada (1982) assumed all mixing lengths proportional to the master length scale, where the constants of proportionality are empirically determined from turbulent flows in laboratory. 
Table 6. First order closure model based on mixing length

( $\lambda$ ) approach.

\begin{tabular}{|c|c|}
\hline Closure & Unknown \\
\hline $\mathrm{K}_{\mathrm{M}}=\lambda^{2}\left[(\partial \overline{\mathrm{u}} / \partial \mathrm{z})^{2}+(\partial \overline{\mathrm{v}} / \partial \mathrm{z})^{2}\right]^{1 / 2}(1-\mathrm{Ri})^{1 / 2}$ & $\lambda, \mathrm{Ri}$ \\
\hline $\mathrm{K}_{\mathrm{H}}=\mathrm{K}_{\mathrm{M}} / \operatorname{Pr} \quad \operatorname{Pr}=0.7$ & \\
\hline $\mathrm{Ri}=\frac{\mathrm{g}}{\theta_{0}} \frac{\partial \bar{\theta} / \partial \mathrm{z}}{(\partial \overline{\mathrm{u}} / \partial \mathrm{z})^{2}+(\partial \overline{\mathrm{v}} / \partial \mathrm{z})^{2}}$ & \\
\hline$\frac{1}{\lambda}=\frac{\phi_{\mathrm{M}}}{\kappa \mathrm{z}}+\frac{1}{\lambda_{\mathrm{o}}}$ & $\lambda_{0}, \phi_{\mathrm{M}}$ \\
\hline$\phi_{\mathrm{M}}= \begin{cases}{[1-15(\mathrm{z} / \mathrm{L})]^{-1 / 4}} & \mathrm{z} / \mathrm{L}<0 \\
{[1+5(\mathrm{z} / \mathrm{L})]^{2}} & \mathrm{z} / \mathrm{L} \geq 0\end{cases}$ & $\mathrm{z} / \mathrm{L}$ \\
\hline$z / L=\left\{\begin{array}{cc}\mathrm{Ri} & \mathrm{Ri}<0 \\
\mathrm{Ri} /(1-5 \mathrm{Ri}) & 0 \leq \mathrm{Ri}<0.20\end{array}\right.$ & - \\
\hline$\lambda_{0}=\mathrm{c}_{0}\left[\left(\overline{\mathrm{u}}_{\mathrm{g}}{ }^{2}+\overline{\mathrm{v}}_{\mathrm{g}}{ }^{2}\right)^{1 / 2} / \mathrm{f} \mid\right] \mathrm{c}_{0}=0.0004$ & \\
\hline
\end{tabular}

Table 7. First order closure model based on turbulent kinetic energy equation ( $11 / 2$ order closure); where e is the turbulent kinetic energy; $\mathrm{e}_{1}=1.2 ; \mathrm{e}_{2}=0.125$ and $\lambda_{\mathrm{e}}$ is the dissipation length scale given by Therry and Lacarrère (1983).

\begin{tabular}{|c|c|}
\hline Closure & Unknown \\
\hline$\frac{\partial \mathrm{e}}{\partial \mathrm{t}}=\mathrm{K}_{\mathrm{M}}\left[\left(\frac{\partial \overline{\mathrm{u}}}{\partial \mathrm{z}}\right)^{2}+\left(\frac{\partial \overline{\mathrm{v}}}{\partial \mathrm{z}}\right)^{2}\right]-\frac{\mathrm{g}}{\theta_{0}} \mathrm{~K}_{\mathrm{H}} \frac{\partial \bar{\theta}}{\partial \mathrm{z}}-\mathrm{e}_{2} \frac{\mathrm{e}^{3 / 2}}{\lambda_{\mathrm{e}}}+\mathrm{e}_{1} \frac{\partial}{\partial \mathrm{z}}\left(\mathrm{K}_{\mathrm{M}} \frac{\partial \mathrm{e}}{\partial \mathrm{z}}\right)$ & $\mathrm{e}, \mathrm{K}_{\mathrm{M}}, \mathrm{K}_{\mathrm{H}}, \lambda_{\mathrm{e}}$ \\
\hline $\mathrm{K}_{\mathrm{M}}=\mathrm{C}_{\mathrm{K}} \lambda \sqrt{\mathrm{e}}$ & $\lambda$ \\
\hline Pr is the turbulent number of Prandtl. & $\operatorname{Pr}$ \\
\hline$\frac{1}{\lambda}=\frac{1}{\kappa \mathrm{z}}+\frac{\mathrm{C}_{\mathrm{K} 1}}{\mathrm{~h}}-\left(\frac{1}{\mathrm{\kappa z}}+\frac{\mathrm{C}_{\mathrm{K} 2}}{\mathrm{~h}}\right) \mathrm{m}_{\mathrm{K} 1} \mathrm{~m}_{\mathrm{K} 2}+\frac{\mathrm{C}_{\mathrm{K} 3}}{\lambda_{\mathrm{s}}} \quad \mathrm{C}_{\mathrm{K} 1}=15, \mathrm{C}_{\mathrm{K} 2}=11$ and $\mathrm{C}_{\mathrm{K} 3}=3$ & $\mathrm{~h}, \mathrm{~m}_{\mathrm{K} 1}, \mathrm{~m}_{\mathrm{K} 2}, \lambda_{\mathrm{s}}$ \\
\hline $\mathrm{m}_{\mathrm{K} 1}=\left[1-\mathrm{C}_{\mathrm{K} 4}(\mathrm{~h} / \mathrm{\kappa z})\right]^{-1}$ & $\mathrm{~h}$ \\
\hline $\mathrm{m}_{\mathrm{K} 2}=\left\{\begin{array}{ll}0 & \mathrm{~L} \geq 0 \\
{\left[1-\mathrm{C}_{\mathrm{K} 5}(\mathrm{~L} / \mathrm{\kappa z})\right]^{-1}} & \mathrm{~L}<0\end{array} \quad \mathrm{C}_{\mathrm{K} 5}=1\right.$ & $\mathrm{L}$ \\
\hline$\frac{1}{\lambda_{\varepsilon}}=\frac{1}{\kappa \mathrm{z}}+\frac{\mathrm{C}_{\mathrm{E} 1}}{\mathrm{~h}}-\left(\frac{1}{\kappa \mathrm{z}}+\frac{\mathrm{C}_{\mathrm{E} 2}}{\mathrm{~h}}\right) \mathrm{m}_{\mathrm{E} 1} \mathrm{~m}_{\mathrm{E} 2}+\frac{\mathrm{C}_{\mathrm{E} 3}}{\lambda_{\mathrm{s}}} \quad \mathrm{C}_{\mathrm{E} 1}=15, \mathrm{C}_{\mathrm{E} 2}=5$ and $\mathrm{C}_{\mathrm{E} 3}=1.5$ & $\mathrm{~h}, \mathrm{~m}_{\mathrm{E} 1}, \mathrm{~m}_{\mathrm{E} 2}, \lambda_{\mathrm{s}}$ \\
\hline $\mathrm{m}_{\mathrm{E} 1}=\left[1-\mathrm{C}_{\mathrm{E} 4}(\mathrm{~h} / \mathrm{\kappa z})\right]^{-1}$ & $\mathrm{~h}$ \\
\hline $\mathrm{m}_{\mathrm{E} 2}=\left\{\begin{array}{ll}0 & \mathrm{~L} \geq 0 \\
{\left[1-\mathrm{C}_{\mathrm{E} 5}(\mathrm{~L} / \kappa \mathrm{z})\right]^{-1}} & \mathrm{~L}<0\end{array} \mathrm{C}_{\mathrm{E} 5}=1\right.$ & $\mathrm{L}$ \\
\hline$\frac{1}{\lambda_{\mathrm{s}}}= \begin{cases}0 & \partial \bar{\theta} / \partial \mathrm{z} \leq 0 \\
\mathrm{~N}_{\mathrm{B}} / \sqrt{\mathrm{e}} & \partial \bar{\theta} / \partial \mathrm{z}>0\end{cases}$ & $\mathrm{e}, \mathrm{N}_{\mathrm{B}}$ \\
\hline $\mathrm{N}_{\mathrm{B}}=\sqrt{\frac{\mathrm{g}}{\theta_{0}} \frac{\partial \bar{\theta}}{\partial \mathrm{z}}}$ & - \\
\hline
\end{tabular}

In Table 8 it is described the set of equations and unknowns. In the parameterization used in SOCM, " $\mathrm{E}$ " is twice the turbulent kinetic energy; $\tau_{\mathrm{IM}}$ and $\tau_{\mathrm{IT}}$ are, respectively, the characteristic time scales for tendency toward isotropy of variance and covariance of momentum and temperature; $\tau_{\mathrm{DM}}$ and $\tau_{\mathrm{DT}}$ are, respectively, the characteristic time scales for molecular dissipation of variance of momentum and temperature; $\mathrm{K}_{\mathrm{M}}$ and $\mathrm{K}_{\mathrm{H}}$ are the coefficients of turbulent diffusion of variance and covariance of momentum and temperature. These scales and coefficients are evaluated in terms of a master length scale. In SOCM the master length, $\lambda$, is 
derived from Blackadar mixing-length expression for neutral conditions where the stability effect is introduced ad hoc by assumptions on the Blackadar expression (Holt and Raman 1988). According to Mellor and Yamada (1982), the determination of master length scale is the major weakness, precluding a more generic application of SOCM. The most relevant parameters and expressions used in the second order closure model are given in Table 9.

Table 8. Set of equations used in the SOCM developed by Mellor and Yamada (1982).

\begin{tabular}{|c|c|}
\hline Equation & Unknown \\
\hline$\frac{\partial \overline{\mathrm{u}}}{\partial \mathrm{t}}=-\frac{\partial \overline{\left(\mathrm{u}^{\prime} \mathrm{w}^{\prime}\right)}}{\partial \mathrm{z}}+\left(-\frac{1}{\rho_{\mathrm{o}}} \frac{\partial \overline{\mathrm{p}}}{\partial \mathrm{x}}+\mathrm{f} \overline{\mathrm{v}}\right)$ & $\overline{\mathrm{u}}, \overline{\left(\mathrm{u}^{\prime} \mathrm{w}^{\prime}\right)}$ \\
\hline$\frac{\partial \overline{\mathrm{v}}}{\partial \mathrm{t}}=-\frac{\partial \overline{\left(\mathrm{v}^{\prime} \mathrm{w}^{\prime}\right)}}{\partial \mathrm{z}}+\left(-\frac{1}{\rho_{\mathrm{o}}} \frac{\partial \overline{\mathrm{p}}}{\partial \mathrm{y}}-\mathrm{f} \overline{\mathrm{u}}\right)$ & $\overline{\mathrm{v}}, \overline{\left(\mathrm{v}^{\prime} \mathrm{w}^{\prime}\right)}$ \\
\hline$\frac{\partial \bar{\theta}}{\partial \mathrm{t}}=-\frac{\partial \overline{\left(\theta^{\prime} \mathrm{w}^{\prime}\right)}}{\partial \mathrm{z}}-\left(\frac{1}{\rho_{0} \mathrm{c}_{\mathrm{P}}} \frac{\partial \mathrm{R}_{\mathrm{N}}}{\partial \mathrm{z}}\right)$ & $\overline{\bar{\theta}}, \overline{\left(\theta^{\prime} w^{\prime}\right)}$ \\
\hline 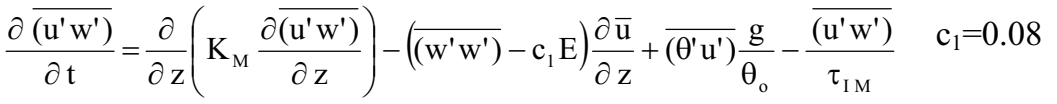 & $\overline{\left(\mathrm{u}^{\prime} \mathrm{w}^{\prime}\right)}, \mathrm{K}_{\mathrm{H}}, \tau_{\mathrm{IM}}$, \\
\hline$\frac{\partial \overline{\left(v^{\prime} w^{\prime}\right)}}{\partial t}=\frac{\partial}{\partial z}\left(K_{M} \frac{\partial \overline{\left(v^{\prime} w^{\prime}\right)}}{\partial z}\right)-\left(\overline{\left(w^{\prime} w^{\prime}\right)}-c_{1} E\right) \frac{\partial \bar{v}}{\partial z}+\overline{\left(\theta^{\prime} v^{\prime}\right)} \frac{g}{\theta_{o}}-\frac{\overline{\left(v^{\prime} w^{\prime}\right)}}{\tau_{\text {IM }}}$ & $\overline{\left(\mathrm{v}^{\prime} \mathrm{w}^{\prime}\right)}, \mathrm{K}_{\mathrm{H}}, \tau_{\mathrm{IM}}, \mathrm{E}$ \\
\hline$\frac{\partial \overline{\left(\theta^{\prime} w^{\prime}\right)}}{\partial \mathrm{t}}=\frac{\partial}{\partial \mathrm{z}}\left(\mathrm{K}_{\mathrm{T}} \frac{\partial \overline{\left(\theta^{\prime} \mathrm{w}^{\prime}\right)}}{\partial \mathrm{z}}\right)-\overline{\left(\mathrm{w}^{\prime} \mathrm{w}^{\prime}\right)} \frac{\partial \bar{\theta}}{\partial \mathrm{z}}+\overline{\left(\theta^{\prime} \theta^{\prime}\right)} \frac{\mathrm{g}}{\theta_{\mathrm{o}}}-\frac{\overline{\left(\theta^{\prime} \mathrm{w}^{\prime}\right)}}{\tau_{\mathrm{IT}}}$ & $\overline{\left(\theta^{\prime} \mathrm{W}^{\prime}\right)}, \mathrm{K}_{\mathrm{H}}, \tau_{\mathrm{IT}}$ \\
\hline$\frac{\partial \overline{\left(\mathrm{u}^{\prime} \mathrm{u}^{\prime}\right)}}{\partial \mathrm{t}}=\frac{\partial}{\partial \mathrm{z}}\left(\mathrm{K}_{\mathrm{M}} \frac{\partial \overline{\left(\mathrm{u}^{\prime} \mathrm{u}^{\prime}\right)}}{\partial \mathrm{z}}\right)-2 \overline{\left(\mathrm{u}^{\prime} \mathrm{w}^{\prime}\right)} \frac{\partial \overline{\mathrm{u}}}{\partial \mathrm{z}}-\left(\frac{3 \overline{\left(\mathrm{u}^{\prime} \mathrm{u}^{\prime}\right)}-\mathrm{E}}{3 \tau_{\mathrm{IM}}}\right)-\frac{2}{3} \frac{\mathrm{E}}{\tau_{\mathrm{DM}}}$ & $\overline{\left(u^{\prime} u^{\prime}\right)}, K_{H}, \tau_{I M}, \tau_{D M}, E$ \\
\hline$\frac{\partial \overline{\left(v^{\prime} v^{\prime}\right)}}{\partial t}=\frac{\partial}{\partial z}\left(K_{M} \frac{\partial \overline{\left(v^{\prime} v^{\prime}\right)}}{\partial z}\right)-2 \overline{\left(v^{\prime} w^{\prime}\right)} \frac{\partial \bar{v}}{\partial z}-\left(\frac{3 \overline{\left(v^{\prime} v^{\prime}\right)}-E}{3 \tau_{I M}}\right)-\frac{2}{3} \frac{E}{\tau_{D M}}$ & $\overline{\left(\mathrm{v}^{\prime} \mathrm{v}^{\prime}\right)}, \mathrm{K}_{\mathrm{H}}, \tau_{\mathrm{IM}}, \tau_{\mathrm{DM}}, \mathrm{E}$ \\
\hline$\frac{\partial \overline{\left(w^{\prime} w^{\prime}\right)}}{\partial t}=\frac{\partial}{\partial z}\left(K_{M} \frac{\partial \overline{\left(w^{\prime} w^{\prime}\right)}}{\partial z}\right)+2 \overline{\left(\theta^{\prime} w^{\prime}\right)} \frac{g}{\theta_{o}}-\left(\frac{3 \overline{\left(w^{\prime} w^{\prime}\right)}-E}{3 \tau_{I M}}\right)-\frac{2}{3} \frac{E}{\tau_{D M}}$ & $\overline{\left(\mathrm{w}^{\prime} \mathrm{w}^{\prime}\right)}, \mathrm{K}_{\mathrm{H}}, \tau_{\mathrm{IM}}, \tau_{\mathrm{DM}}, \mathrm{E}$ \\
\hline$\frac{\partial \overline{\left(\theta^{\prime} u^{\prime}\right)}}{\partial t}=\frac{\partial}{\partial z}\left(K_{T} \frac{\partial \overline{\left(\theta^{\prime} u^{\prime}\right)}}{\partial z}\right)-\overline{\left(\theta^{\prime} w^{\prime}\right)} \frac{\partial \bar{u}}{\partial z}-\overline{\left(u^{\prime} w^{\prime}\right)} \frac{\partial \bar{\theta}}{\partial z}-\frac{\overline{\left(\theta^{\prime} u^{\prime}\right)}}{\tau_{\text {IT }}}$ & $\overline{\left(\theta^{\prime} \mathrm{u}^{\prime}\right)}, \mathrm{K}_{\mathrm{H}}, \tau_{\mathrm{IT}}$ \\
\hline$\frac{\partial \overline{\left(\theta^{\prime} v^{\prime}\right)}}{\partial t}=\frac{\partial}{\partial z}\left(K_{T} \frac{\partial \overline{\left(\theta^{\prime} v^{\prime}\right)}}{\partial z}\right)-\overline{\left(\theta^{\prime} w^{\prime}\right)} \frac{\partial \bar{v}}{\partial z}-\overline{\left(v^{\prime} w^{\prime}\right)} \frac{\partial \bar{\theta}}{\partial z}-\frac{\overline{\left(\theta^{\prime} v^{\prime}\right)}}{\tau_{\text {IT }}}$ & $\overline{\left(\theta^{\prime} \mathrm{v}^{\prime}\right)}, \mathrm{K}_{\mathrm{H}}, \tau_{\mathrm{IT}}$ \\
\hline$\frac{\partial \overline{\left(\theta^{\prime} \theta^{\prime}\right)}}{\partial \mathrm{t}}=\frac{\partial}{\partial \mathrm{z}}\left(\mathrm{K}_{\mathrm{T}} \frac{\partial \overline{\left(\theta^{\prime} \theta^{\prime}\right)}}{\partial \mathrm{z}}\right)-2 \overline{\left(\theta^{\prime} \mathrm{w}^{\prime}\right)} \frac{\partial \bar{\theta}}{\partial \mathrm{z}}-\frac{\overline{\left(\theta^{\prime} \theta^{\prime}\right)}}{\tau_{\mathrm{DT}}}$ & $\overline{\overline{\left(\theta^{\prime} \theta^{\prime}\right)}, \mathrm{K}_{\mathrm{H}}, \tau_{\mathrm{DT}}}$ \\
\hline
\end{tabular}

Figures 4 and 5 show, as example, vertical profiles of different meteorological parameters generated by numerical simulation using SOCM. The results correspond to the 12:00 LT, in Ipero $\left(23^{\circ} 25^{\prime} \mathrm{S}\right.$ and $47^{\circ}$ $35^{\prime}$ W), São Paulo, during winter.

\section{LARGE EDDY SIMULATION MODEL (LES)}

In the last 30 years the LES model has been applied to investigate several features of the turbulence in the atmospheric PBL under convective, neutral and stable regimes (Mason, 1994; Lesieur and Métais, 1996). An example of these applications can be seen in Table 10. In
Table 10 one can see that in 90's the LES reached an extraordinary spatial resolution with numerical simulations using grid size of 2 meters and spatial domains with $10^{6}$ grid points (Andrén, 1995; Su et al., 1998).

Deardorff (1972) carried out the first simulations of the convective PBL, using LES, and verified that the convective wind velocity $\left(\mathrm{W}_{*}\right)$ and the PBL height $\left(\mathrm{z}_{\mathrm{i}}\right)$ were the characteristic scales that formed the mixed layer similarity. In these remarkable simulations, Deardorff carried also out estimates of the turbulent diffusion of atmospheric pollutants by following the trajectories of a set of particles released in the PBL. Later, his results 
were extensively used to develop a set of atmospheric dispersion parameters intensively applied in Lagrangian Particle Models (Lamb, 1984).
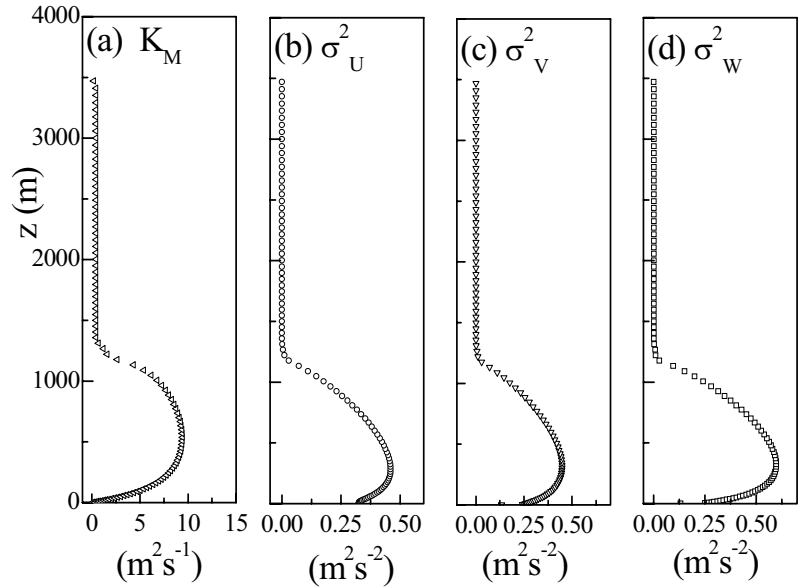

Figure 4. Vertical profiles of (a) diffusion coefficient, (b) variance of zonal, (c) meridional and (d) vertical components of the wind velocity. Numerical simulation using SOCM. The results correspond to the 12:00 LT, in Iperó, São Paulo, during winter.
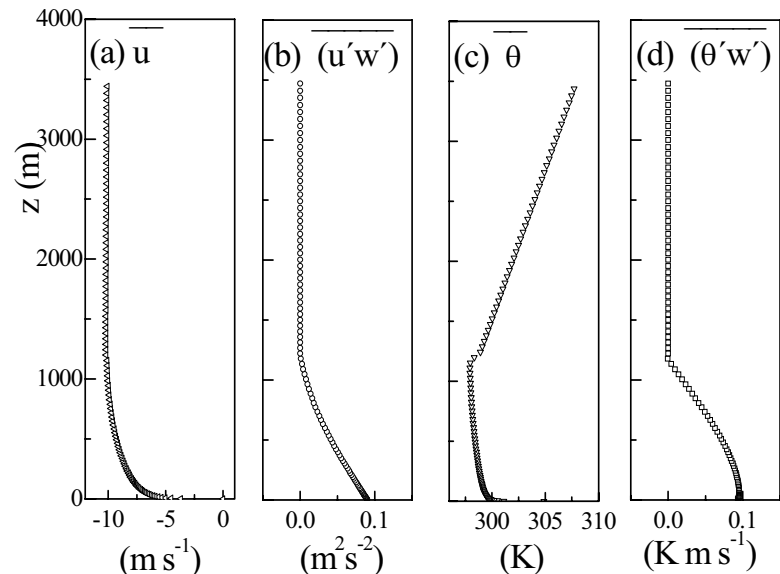

Figure 5. Vertical profiles of (a) zonal component of the wind velocity, (b) vertical turbulent flux of zonal component, (c) potential temperature and (d) vertical turbulent flux of sensible heat flux. Numerical simulation of the PBL by one-dimension SOCM, with 81 grid points in the vertical directions. The results correspond to 12:00 LT in Ipero, São Paulo, during winter (Karam, et al., 2001)
Table 9. Second order closure proposed by Mellor and Yamada (1982).

\begin{tabular}{|c|c|}
\hline Equation & Unknown \\
\hline $\mathrm{K}_{\mathrm{M}}=0.12 \lambda \sqrt{\mathrm{E}}$ & $\lambda, \mathrm{E}$ \\
\hline$\tau_{\mathrm{IM}}=(0.92 \lambda) / \sqrt{\mathrm{E}}$ & $\lambda, \mathrm{E}$ \\
\hline$\tau_{\mathrm{DM}}=(16.6 \lambda) / \sqrt{\mathrm{E}}$ & $\lambda, \mathrm{E}$ \\
\hline $\mathrm{K}_{\mathrm{H}}=0.20 \lambda \sqrt{\mathrm{E}}$ & $\lambda, \mathrm{E}$ \\
\hline$\tau_{\mathrm{DT}}=(10.1 \lambda) / \sqrt{\mathrm{E}}$ & $\lambda, \mathrm{E}$ \\
\hline$\frac{1}{\lambda}=\frac{1}{\mathrm{kz}}+\frac{1}{\lambda_{0}}$ & $\lambda_{0}$ \\
\hline$\frac{1}{\lambda_{0}}=10\left[\int_{0}^{\mathrm{h}} \sqrt{\mathrm{E}} \mathrm{dz} / \int_{0}^{\mathrm{h}} \sqrt{\mathrm{E}} \mathrm{zdz}\right]$ & $\mathrm{E}$ \\
\hline $\mathrm{E}=2 \mathrm{e}=\overline{\left(\mathrm{u}^{\prime} \mathrm{u}^{\prime}\right)}+\overline{\left(\mathrm{v}^{\prime} \mathrm{v}^{\prime}\right)}+\overline{\left(\mathrm{w}^{\prime} \mathrm{w}^{\prime}\right)}$ & \\
\hline
\end{tabular}

Table 10. Characteristics of the LES used to simulate PBL turbulence.

\begin{tabular}{|l|c|c|c|c|}
\hline \multicolumn{1}{|c|}{ Author } & $\begin{array}{c}\text { Number of } \\
\text { grid points } \\
(\mathbf{x}, \mathbf{y}, \mathbf{z})\end{array}$ & $\begin{array}{c}\text { Model } \\
\text { domain } \\
(\mathbf{x}, \mathbf{y}, \mathbf{z}) \\
\left(\mathbf{k m}^{\mathbf{3}}\right)\end{array}$ & $\begin{array}{c}\text { Time } \\
\text { Step } \\
\mathbf{( s )}\end{array}$ & $\begin{array}{c}\text { Total } \\
\text { integration } \\
\text { time (h) }\end{array}$ \\
\hline $\begin{array}{l}\text { Deardorff } \\
(1972)\end{array}$ & $40,40,20$ & $4 \times 4 \times 1$ & - & - \\
\hline $\begin{array}{l}\text { Deardorff } \\
(1974)\end{array}$ & $40,40,40$ & $5 \times 5 \times 2$ & - & 8 \\
\hline $\begin{array}{l}\text { Moeng } \\
(1984)\end{array}$ & $32,32,40$ & $5 \times 5 \times 2$ & 3 & 7 \\
\hline $\begin{array}{l}\text { Wyngaard } \\
\text { and Brost } \\
(1984)\end{array}$ & $40,40,40$ & $5 \times 5 \times 2$ & - & 1 \\
\hline $\begin{array}{l}\text { Van Haren } \\
\text { and } \\
\begin{array}{l}\text { Nieuwstadt } \\
(1989)\end{array}\end{array}$ & $40,40,40$ & $5 \times 5 \times 2$ & 5 & - \\
\hline $\begin{array}{l}\text { Moeng and } \\
\text { Wyngaard } \\
(1989)\end{array}$ & $96,96,96$ & $5 \times 5 \times 2$ & - & - \\
\hline $\begin{array}{l}\text { Moeng and } \\
\text { Sullivan } \\
(1994)\end{array}$ & $96,96,96$ & $5 \times 5 \times 2$ & - & 3 \\
\hline $\begin{array}{l}\text { Andrén } \\
(1995)\end{array}$ & $96,96,96$ & $0.6 \times 0.4 \times$ \\
\hline $\begin{array}{l}\text { Su } \text { et al. } \\
(1998)\end{array}$ & $96,96,30$ & $0.192 \times$ & - & - \\
\hline
\end{tabular}

In the LES models, in order to describe the spatial scales of motion larger than a particular cutoff scale it is necessary to apply a low pass filter to the mass, momentum and energy equations. To explicitly describe only motions with length scales larger than a determined valor $\delta$ is convenient to use a low pass filter: $\left\langle f\left(x_{i}, t\right)\right\rangle=\int G\left(x-x_{i}^{\prime}\right) f\left(x_{i}^{\prime}, t\right) d x_{i}^{\prime}$, where $f$ is any variable 
and $\mathrm{G}$ is a filter function, $x_{i}$ is the coordinate in the $i$ direction and $t$ is time. The resulting momentum and thermodynamic equations are given in Table 11.

The results presented hereafter are based on the three-dimensional fields generated after the first 1000 time steps (approximately 0.8 hours), when the convective boundary layer has reached an state of equilibrium, using LES model developed by Moeng and Sullivan (1994). It was selected 6 outputs (realizations), 200 time steps away from each other, from time step 1000 to 2000.

Figure (6a) shows vertical profiles of horizontal-plane average, for each of the 6 realizations, for the skewness. It also includes one vertical profile of an ensemble average of these 6 horizontal-plane averages. The second-order and third-order statistical moments were calculated considering the fluctuations of resolved-scale with respect to the horizontal-plane average. Figures $(6 \mathrm{~b})$ and $(6 \mathrm{c})$ correspond to the instantaneous vertical component velocity and a pollutant concentration fields, simulated after 1000 time steps. In Fig. (6b) it is possible to identify at least one well-defined updraft (darker region between $3000 \mathrm{~m}<\mathrm{x}<3800 \mathrm{~m})$. The extensive regions of weak vertical motion are the downdrafts. The updraft penetrates the inversion capping inducing descend motion which brings dry and "clean air" of the stable layer above into the CBL. This entrainment of clean air decreases the pollutant concentration near $z_{i}$, between $800 \mathrm{~m}<\mathrm{z}<1500 \mathrm{~m}$ (Fig. 6c).

Table 11. Equation of motion used in LES models, in tensor notation, where $\delta_{\mathrm{i} 3}$ is the Kronecker delta and $\varepsilon_{\mathrm{ijk}}$ is the LeviCivita tensor. The vector $\Omega_{j}$ is the Earth rotation rate and $v_{0}$ and $\kappa_{0}$ are, respectively, the kinematics viscosity and thermal diffusivity of the air. The sub-grid turbulence terms are $\tau_{\mathrm{ij}}=-\left(\left\langle\mathrm{u}_{\mathrm{i}} \mathrm{u}_{\mathrm{j}}\right\rangle-\left\langle\mathrm{u}_{\mathrm{i}}\right\rangle\left\langle\mathrm{u}_{\mathrm{j}}\right\rangle\right)$ and $\tau_{\theta j}=-\left(\left\langle\theta \mathrm{u}_{\mathrm{j}}\right\rangle-\langle\theta\rangle\left\langle\mathrm{u}_{\mathrm{j}}\right\rangle\right)$.

\begin{tabular}{|c|c|}
\hline Equation & Unknown \\
\hline$\frac{\partial\left\langle\mathrm{u}_{\mathrm{i}}\right\rangle}{\partial \mathrm{t}}+\frac{\left.\partial\left\langle\mathrm{u}_{\mathrm{j}}\right\rangle \mathrm{u}_{\mathrm{i}}\right\rangle}{\partial \mathrm{x}_{\mathrm{j}}}=-\frac{1}{\rho_{0}} \frac{\partial\langle\mathrm{p}\rangle}{\partial \mathrm{x}_{\mathrm{i}}}-\mathrm{g} \delta_{\mathrm{ij}}+\frac{\langle\theta\rangle-\theta_{0}}{\theta_{0}} \mathrm{~g} \delta_{\mathrm{i} 3}-2 \varepsilon_{\mathrm{ijk}} \Omega_{\mathrm{j}}\left\langle\mathrm{u}_{\mathrm{k}}\right\rangle+\frac{\partial}{\partial \mathrm{x}_{\mathrm{j}}}\left(\mathrm{v}_{0} \frac{\partial\left\langle\mathrm{u}_{\mathrm{i}}\right\rangle}{\partial \mathrm{x}_{\mathrm{j}}}+\tau_{\mathrm{ij}}\right)$ & $\left\langle\mathrm{u}_{\mathrm{i}}\right\rangle,\langle\mathrm{p}\rangle, \tau_{\mathrm{ij}}$ \\
\hline$\frac{\partial\langle\theta\rangle}{\partial t}+\frac{\partial\left\langle u_{j}\right\rangle\langle\theta\rangle}{\partial x_{j}}=-\frac{1}{c_{p} \rho_{0}} \frac{\partial\left\langle\mathrm{Rn}_{j}\right\rangle}{\partial x_{j}}+\frac{\partial}{\partial x_{j}}\left(k_{0} \frac{\partial\langle\theta\rangle}{\partial x_{j}}+\tau_{\theta j}\right)$ & $\langle\theta\rangle, \tau_{\theta \mathrm{j}}$ \\
\hline$\frac{\partial\left\langle\mathrm{u}_{\mathrm{i}}\right\rangle}{\partial \mathrm{x}_{\mathrm{i}}}=0$ & - \\
\hline$-\left(\langle\rho\rangle-\rho_{0}\right) / \rho_{0}=\left(\langle\theta\rangle-\theta_{0}\right) / \theta_{0}$ & $\langle\rho\rangle,\langle\theta\rangle$ \\
\hline$\frac{1}{\rho_{0}} \frac{\partial^{2}\langle\mathrm{p}\rangle}{\partial \mathrm{x}_{\mathrm{i}}^{2}}=-\frac{\partial\left\langle\mathrm{u}_{\mathrm{j}}\right\rangle}{\partial \mathrm{x}_{\mathrm{i}}} \frac{\partial\left\langle\mathrm{u}_{\mathrm{i}}\right\rangle}{\partial \mathrm{x}_{\mathrm{j}}}+\frac{\partial}{\partial \mathrm{x}_{\mathrm{i}}}\left(\frac{\partial \tau_{\mathrm{ij}}}{\partial \mathrm{x}_{\mathrm{j}}}\right)+\frac{\mathrm{g} \delta_{\mathrm{i}}}{\theta_{0}} \frac{\partial\left(\langle\theta\rangle-\theta_{0}\right)}{\partial \mathrm{x}_{\mathrm{i}}}-2 \varepsilon_{\mathrm{ijk}} \Omega_{\mathrm{j}} \frac{\partial\left\langle\mathrm{u}_{\mathrm{k}}\right\rangle}{\partial \mathrm{x}_{\mathrm{i}}}$ & $\langle\mathrm{p}\rangle$ \\
\hline
\end{tabular}
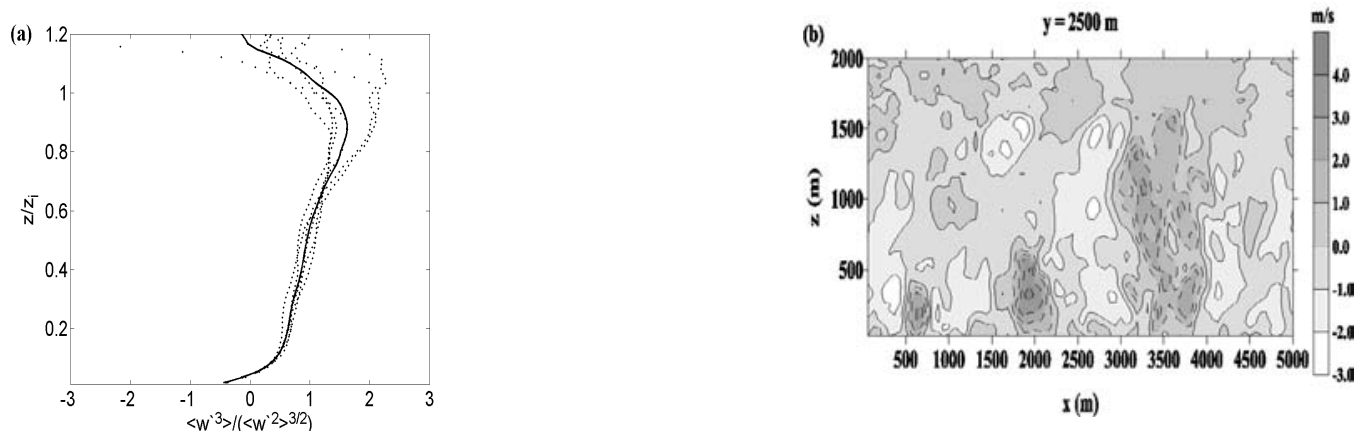

$I(m)$ 


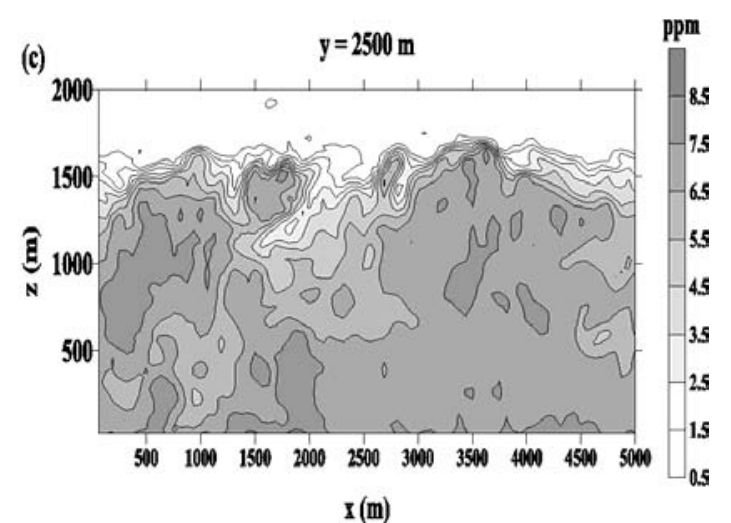

Figure 6. (a) The vertical profile of the skewness. Numerical simulation using LES with $80^{3}$ grid points in a domain of $5 \mathrm{kmx} 5 \mathrm{kmx} 2 \mathrm{~km}$. Forcing and boundary conditions were set to generate highly convective PBL reaching equilibrium for $z / L=-800$; (b) Contour map of vertical wind velocity (in $\mathrm{m} \mathrm{s}^{-1}$ ) in a cross section in $y=2500 \mathrm{~m}$. Simulation using LES for convective conditions. After 1000 time steps and (c) The contour map of CO concentration (ppm) in a cross section in $\mathrm{y}=2500 \mathrm{~m}$. Simulation using LES. For convective conditions. After 1000 time steps.

\section{CONCLUSION}

In this paper the major techniques used to model numerically the PBL are reviewed, and some numerical results are shown. The Monin-Obukhov, Free Convection, Mixed Layer Similarities theories can be applied to diagnose the PBL vertical structure under equilibrium conditions. The four similarities laws can be applied to second order statistic moments and their spectral distribution.

Prognostic models are classified in four categories: (a) bulk; (b) first order closure; (c) second order closure and (d) large eddy simulation models. The numerical simulation displayed here indicated that first order closure using turbulent kinetic energy equation is more indicated in most of the meteorological mesoscale models. It combines simplicity and a better physical description of turbulent transport when compared with mixing length approach.

The second order closure model has now become a reasonable alternative for the first order closure. It requires a diagnostic equation for the master length scale but provides a complete description of the second order moments in the PBL.

The large eddy simulation models unravel important features of the PBL structure that are inaccessible to other numerical techniques of modeling. The greatest limitation for LES model application is computational. It requires high performance computers with large I/O capacity. For instance in the simulation displayed here a CRAY J90 took about 4 days of CPU time to simulate 3600 time steps.

\section{ACKNOWLEDGEMENTS}

The authors acknowledge financial support provided by "Conselho Nacional de Desenvolvimento Científico e Tecnológico - CNPq" and by "Fundação de Amparo à Pesquisa do Estado de São Paulo - Fapesp". The LES model simulations were carried out in the Cray J90 of LCCA/USP.

\section{REFERENCES}

Andrén, A., 1995, "The Structure of Stably Stratified Atmospheric Boundary Layers: A Large-Eddy Simulation Study". Quartely Journal Royal Met. Society, 121(525), 961-985.

Avissar, R., Moran, M.D., Wu, G., Meroney, R.N., and Pielke, R. A., 1990, "Operating Ranges of Mesoscale Numerical Models and Meteorological Wind Tunnels for the Simulation of Sea and Land Breezes". BoundaryLayer Meterology, 50, 227-275.

Cermak, J. E., 1995, "Physical Modeling of Flow and Dispersion over Urban Areas", in: Cermak, J. E., Davenport, A. G., Plate, E. J., Viegas, D. X. Ed. Wind Climate in Cities. Kluwer: Dordrecht, Netherlands, 383403.

Deardorff, J. W., 1972, "Numerical Investigation of Neutral and Unstable Planetary Boundary Layers". Journal of the Atmospheric Sciences, 29, 91-115.

Deardorff, J.W. 1974, "Three-Dimensional Numerical Study of Turbulence in an Entraining Mixed Layer". Boundary-Layer Meteorology, 7,199-226.

Deardorff, J. W. 1980, "Progress in understanding Entrainment at the top of the Mixed Layer", in Workshop on Planetary Boundary Layer, American Meteorological Society, $322 \mathrm{pp}$.

Dutton, J. A., Fitchl, G.H., 1969, "Approximate Equations of Motion for Gases and Liquids". Journal of the Atmospheric Sciences, 26, 241-254.

Frisch, U., 1995, Turbulence, Cambridge, Cambridge Press, 296 pp.

Garratt, J. R., Hess, G. D., Physick, W. L. and Bougeault, P., 1996, "The Atmospheric Boundary Layer - Advances in Knowledge and Application". BoundaryLayer Meteorology, 78, 9-37.

Hojstrup, J, 1982, "Velocity Spectra in the Unstable Planetary Boundary Layer". Journal of Atmospheric Sciences, 39, 2239-2248.

Kaimal, J.C. and J.J. Finnigan, 1994, Atmospheric Boundary Layer Flows, Oxford University Press.

Holt, T. and Raman, S., 1988, "A Review and Comparative Evaluation of Multilevel Boundary Layer Parameterizations for First-Order and Turbulent Kinetic 
Energy Closure Schemes". Review of Geophysics., 26, 761-780.

Karam, H. A., Oliveira, A. P. and Pereira, M. M., 2001, "Application of a Lagrangian Model to Investigate Patterns of Radionuclides Dispersion Over Complex Terrain - Part 1: Local Circulation and Low-Level Jet", in Proceedings of the Seventh International Conference on Harmonization within Atmospheric Dispersion Modeling for Regulatory Purposes, May 28-31, Belgirate, Italy, 395-399.

Lamb, R. G., 1984, "Diffusion in the Convective Boundary Layer", in: Nieuwstadt, F. T. M., van Dop, H. Ed. Atmospheric Turbulence and Air Pollution Modeling. 1.ed. Reidel:Dordrecht, 159-229.

Lesieur, M. and Métais, O, 1996, "New Trends in LargeEddy Simulation of Turbulence", Annual Rev. Fluids Mech., 28, 45-82.

Lu, J. and Arya, S. P., 1995, "A Laboratory Simulation of Urban Heat-Island-Induced Circulation in a Stratified Environment", in: Cermak, J. E., Davenport, A. G., Plate, E. J., Viegas, D. X. Ed. Wind Climate in Cities. Kluwer: Dordrecht, Netherlands, 405-429.

Mahrt, L., 1986, "On the Shallow Motion Approximations", Journal of the Atmospheric Sciences, 43(10), 1036-1044.

Mason, P. J., 1994, "Large-Eddy Simulation: A Critical Review of the Technique", Quarterly Journal Royal Met. Society, 120, 1-26.

Mellor, G.L. and Yamada,T., 1982, "Development of a Turbulence Closure Model for Geophysical Fluid Problems", Rev. of Geophys. and Space Phys., 20, 851875.

Moeng, C., 1984, “A Large-Eddy-Simulation Model for the Study of Planetary Boundary-Layer Turbulence", Journal of the Atmospheric Sciences, 41(13), 2052-2062.

Moeng, C. and Wyngaard, J. C., 1986, "An Analysis of Closures for Pressure-Scalar Covariances in the Convective Boundary Layer", Journal of the Atmospheric Sciences, 43(21), 2499-2513.

Moeng, C. and Wyngaard, J. C., 1989, "Evaluation of Turbulent Transport and Dissipation Closures in Second-Order Modeling", Journal of the Atmospheric Sciences, .46(14). 2311-2330.

Moeng, C. and Sullivan, P. P., 1994, “A Comparison of Shear- and Buoyancy-Driven Planetary Boundary Layer Flows", Journal of the Atmospheric Sciences, 51(7), 999-1022.

Monin. A. S. and Yaglom, A. M., 1971, Statistical Fluid Mechanics, Vol. 1, Massachusetts, MIT Press, 769 pp.

Nieuwstadt, F. T. M., 1984, "The Turbulent Structure of the Stable, Nocturnal Boundary Layer", Journal of the Atmospheric Sciences, 41(14), 2202 - 2216.

Oliveira, A.P., Soares, J., Tirabassi, T. and Rizza, U., 1998, "A surface energy budget model coupled with a skewed puff model for investigation the dispersion of radionuclides in a Subtropical area of Brazil", Il Nuovo Cimento, 21C(6), 631-646.

Panofsky, H.A. and Dutton, J.A., 1984, Atmospheric Turbulence - Models and Methods for Engineering Applications, John Wiley, New York, 397 pp.397.
She, Z., Jackson, E., Orszag, M., 1991, “A. Structure and Dynamics of Homogeneous Turbulence: Models and Simulations", Proc. R. Soc. London, 434, 101-124.

Sorbjan, Z, 1989, Structure of the Atmospheric Boundary Layer, Prentice, New Jersey, 317 pp.

Stull, R. B., 1988, An Introduction to Boundary Layer Meteorology, Dordrecht: Kluwer, 666 pp.

Stivari, S.M.S, Oliveira, A. P., Karam, H.A. and Soares, J., 2003, "Patterns of Local Circulation in the Itaipu Lake Area: Numerical Simulations of Lake Breeze", Journal of Applied Meteorology. 42(1), 37-50.

Su, H., Shaw, R. H., Paw U, K. T., Moeng, C. and Sullivan, P. P., 1998, "Turbulent Statistics of Neutrally Stratified Flow within and above a Sparse Forest from Large-Eddy Simulation and Field Observations". Boundary-Layer Meteorology, 88, 363-397.

van Haren, L. and Nieuwstadt, F. T. M., 1989, "The Behavior of Passive and Buoyant Plumes in a Convective Boundary Layer, as Simulated with a Large-Eddy Model", Journal Applied Meteorology, 28, 818-832.

Wyngaard, J. C., 1984, "Boundary Layer Modeling", in: Nieuwstadt, F. T. M., van Dop, H. Ed. Atmospheric Turbulence and Air Pollution Modeling. 1.ed. Reidel:Dordrecht, 69-106.

Wyngaard, J.C., 1985, "Structure of the Planetary Boundary Layer and Implications for its modeling", Journal of Atmospheric Science, 24, 1131-1142.

Wyngaard, J. C. and Brost, R. A., 1984, “Top-Down and Bottom-Up Diffusion of a Scalar in the Convective Boundary Layer", Journal of the Atmospheric Sciences, 41(1), 102-112. 